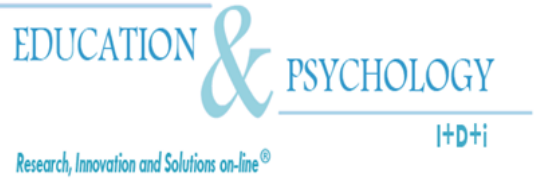

\section{Electronic Journal of Research}

in Educational Psychology

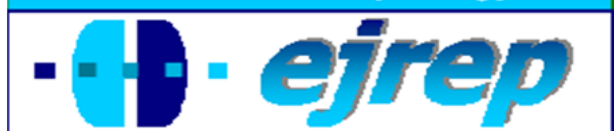

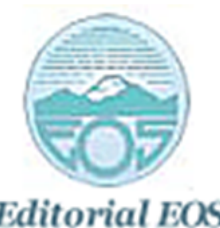

Editorial EOS

\title{
The effectiveness of a program based on self-regulated strategy development on the writing skills of writing-disabled secondary school students
}

\section{Mourad Ali Eissa}

Center for Total Quality and Accreditation, Zagazig University, Kafr El Sheikh

\section{Egypt}

Dr. Mourad Ali Eissa. Head of Center for Total Quality and Accreditation, Zagazig University. Kafr El Sheikh, Egypt. E-mail: eissa33511@yahoo.com 


\begin{abstract}
Introduction. Writing poses challenges for many students. In Egypt, many students with learning disabilities (LD) who learn English as a foreign language exhibit deficiencies in the writing process. In order for students to achieve a good level of competence, those students need to apply strategies which have proven to be effective in improving levels of writing in English. The focus of the research is to explore the effectiveness of program based on the self-regulated strategy development of writing skills in writing-disabled secondary school students.
\end{abstract}

Method. A total of 67 students identified with LD were invited to participate. The sample was randomly divided into two groups; experimental $(\mathrm{n}=34 ; 20$ boys and 14 girls $)$ and control ( $\mathrm{n}=33,20$ boys, 13 girls). ANCOVA and Repeated Measures Analyses were employed for data analysis.

Results. Findings from this study indicated the effectiveness of the program employed in improving the writing performance of the students in the experimental group.

Discussion. On the basis of the findings, the study advocates for the effectiveness of SelfRegulated Strategy Development (SRSD) in improving the writing performance of students in the experimental group.

Keywords: Self regulated learning, Self-Regulated Strategy Development (SRSD), writing skills, Secondary Education, learning disabilities.

Received: 11/18/08 Initial Acceptance: 12/01/08_ Final Acceptance: 01/29/09 


\section{Resumen}

Introducción. Escribir supone desafíos y retos para muchos alumnos. Como consecuencia de ello, en Egipto, muchos alumnos con dificultades de aprendizaje (DA), que aprenden inglés como lengua extranjera, presentan deficiencias en su proceso de escritura. Para que estos alumnos puedan lograr un adecuado nivel de eficacia o competencia en la escritura, necesitan aplicar estrategias, cuya eficacia para la mejora del nivel o competencia de escritura en inglés haya sido probada previamente. El objetivo de esta investigación es analizar la efectividad de un programa centrado en el desarrollo de estrategias de auto-regulación de la escritura en alumnos de Educación Secundaria que presentan dificultades de aprendizaje de la escritura.

Método. Un total de 67 alumnos diagnosticados con DA fueron invitados a participar en el presente estudio. La muestra fue dividida de forma aleatoria en dos grupos: experimental $(\mathrm{N}=$ 34; 20 chicos y 14 chicas), y control ( $\mathrm{N}=33,20$ chicos, 13 chicas). Para los análisis estadísticos se emplearon: ANCOVA y análisis de medidas repetidas.

Resultados. Los resultados obtenidos en el estudio indicaron la efectividad del programa utilizado para la mejora del rendimiento en la escritura de los alumnos objeto del estudio.

Discusión. En base a los resultados obtenidos, el estudio apoya la efectividad del modelo de desarrollo estratégico auto-regulado (Self-Regulated Strategy Development Model - SRSD) para la mejora del rendimiento en escritura de alumnos con dificultades de aprendizaje.

Palabras clave: aprendizaje auto-regulado, modelo de desarrollo estratégico auto-regulado (SRSD), habilidades de escritura, educación secundaria, dificultades de aprendizaje. 


\section{Introduction}

Writing poses challenges for many students. While composing, a writer must manage complex problem-solving processes in writing that include planning, considering the audience's needs and perspectives, generating organized content, and revising for form and ideas. Although many students struggle occasionally with writing, writing is especially difficult for less skilled writers and writers with a learning disability (LD) (Mourad Ali, 2007).

For many students with LD, writing problems exist on two levels: (a) lower levelincluding grammar, punctuation, and spelling; and (b) higher level-including audience awareness, planning, content generation, and revising (Newcomer, Nodine, \& Barenbaum, 1988). Obstacles on either level may detract from the overall quality of the written message. For example, spelling errors may make stories more difficult to understand, while lack of audience awareness may make the story unappealing or irrelevant.

Several research programs have examined how students with LD can be assisted to develop more sophisticated approaches to writing, including the strategies and self-regulation procedures used by more skilled writers (Englert \& Mariage 1991; Wong, Butler, Ficzere, Kuperis, Corden, \& Zlmer, 1994). Karen Harris, Steve Graham, and their colleagues have conducted a research program examining application of the Self-Regulated Strategy Development (SRSD) model to the teaching of writing, as well as the integration of SRSD and the process approach to writing (Graham \& Harris, 1996; Graham, Harris, MacArthur, \& Schwartz, 1991). With SRSD, students collaborate in the development of strategies for planning and revising as well as in developing procedures for regulating the use of these strategies, the writing task, and individual cognitive and behavioral characteristics (such as impulsivity) that may impede writing performance. This approach has been successful in helping students with LD develop strategies for brainstorming (Harris \& Graham, 1985), semantic webbing (MacArthur, Schwartz, Graham, Molloy, \& Harris, 1996), using text structure to generate possible writing content (Danoff, Harris, \& Graham, 1993; De La Paz \& Graham, 1997; Graham \& Harris, 1989), setting goals (Graham, MacArthur, \& Schwartz, 1995), peer response in revising (MacArthur, Schwartz, \& Graham, 1991), and revising for both mechanics and substance (Graham et al., 1992). In over 15 studies conducted to date by Harris, Graham, and their colleagues, or by independent researchers, SRSD has provided an effective 
means for teaching writing and self-regulation strategies to students with LD, resulting in improvements in both the quantity and quality of writing (cf. Harris, Graham, \& Schmidt, 1997).

Therefore, the present study addresses the following two questions:

1- Are there differences in mean post-test scores between control and experimental groups on writing achievement?

2- If the programme is effective, is this effect still evident a month later?

\section{Writing difficulties exhibited by students with learning disabilities}

Students with LD often experience difficulty when asked to plan, write, and revise an essay. In general, these students lack a basic knowledge about how to approach writing and the writing process as a whole. Mourad Ali \& Fadlon Saad (2007) identified five areas of competence that are particularly problematic for students with LD when developing an essay: (a) generating content, (b) creating and organizing structure for compositions, (c) formulating goals and higher-level plans, (d) quickly and efficiently executing the mechanical aspects of writing, and (e) revising text and reformulating goals.

Generating content for an essay typically begins with brainstorming. During this prewriting phase, writers take time to reflect on their topic, select an audience, and develop ideas. Skilled writing depends, in large part, on a student's ability during this phase to plan before composing. MacArthur and Graham (1987) found that students with LD do not spend much time preparing to write. Instead, they often begin writing as soon as they are given an assignment with little or no preparation. Furthermore, students with LD tend to rely on an associative technique wherein they simply write whatever comes to mind (Thomas, Englert, \& Gregg, 1987). Beginning to write immediately after receiving an assignment does not allow adequate goal setting or planning - two important techniques applied by successful writers. Moreover, students with LD appear unsure of what to do when they are given time to plan (Burtis, Bereiter, Scardamalia, \& Tetroe, 1983). Many students with LD do not regard strategies in the prewriting phase as valuable tools and fail to utilize meaningful techniques to become successful writers. 
Students with LD also experience difficulty when attempting to generate content and organize a structure for compositions (Graham, 1990). This problem may be attributed to their under-utilization of strategies for retrieving useful information. Thus, these students frequently view a writing assignment as a question/answer task involving little preparation. In Graham's study, for example, when students with disabilities were given an opinion essay, they simply responded by writing "yes" or "no" (to agree or disagree), followed by a few brief reasons, and ended with no concluding statement. Graham's study demonstrated that, once students with disabilities believe they have answered a question, they often abruptly end their composition without a summation of their point of view. The end result is that very little content is generated. Barenbaum, Newcomer, and Nodine (1987) noted a similar finding: that students with LD produced substantially shorter and lower-quality stories than students who are typically achievers. In most essays that Barenbaum et al. examined, the students with LD failed to frame their stories to include all of the basic elements. Instead, they generated relevant information from memory without any self-regulation, resulting in essays that were generally less coherent and organized than those of their peers without disabilities (MacArthur \& Graham, 1987).

Formulating goals and objectives, a strategy that experienced writers use to plan and execute higher-level writing tasks, is a third area of difficulty for students with LD (Graham, Harris, MacArthur, \& Schwartz, 1991). Writing can be characterized as a problem-solving task that includes identifying goals for writing as well as the means to achieve them. During and after writing, these goals are assessed to determine whether a student needs to redefine the goals or continue with the writing process. In a study by Graham, MacArthur, Schwartz, and Voth (1992), students chose from a list of goals that they felt their paper should accomplish. Students were then taught a strategy that broke the writing task into several parts: (a) generate product and process goals, (b) develop notes, (c) organize notes, (d) write and continue the process of planning, and (e) evaluate success at obtaining goals. After being taught the goal-setting strategy, students met the goals they had set for their essays $90 \%$ of the time.

Many students with LD seem to be unable to quickly and effectively execute the mechanical aspects of writing. Specifically, in comparison to their peers, they make considerably more spelling, capitalization, and punctuation errors in their compositions (MacArthur, Graham, Schwartz, \& Scafer, 1995), and their handwriting is less legible (MacArthur, Graham, \& Skarvold, 1986). Basic skills like spelling, grammar, and handwriting are usually not taught at 
the high school level. It is likely that students with LD will continually lag behind their peers without disabilities if not taught specific strategies to improve the mechanics of their writing.

Sentence formation also tends to be problematic for some students with LD. They often lack a well-developed sense of sentence style and produce short and "choppy" sentences (Kline, Schumaker \& Deshler, 1991). Thus, the repetition of simple sentences and frequent use of run-on sentences are common mistakes exhibited by these students. By comparison, experienced writers edit for the conventions of writing as they proceed with composing their ideas and during the post-writing stage for refinement.

A final area of difficulty for students with LD is the revision of their writing. The revision process is an essential step that requires writers to "rethink" a portion of their writing by editing and rereading it many times, all the while appraising how effectively the written product communicates their intent to the audience. Students with LD often view the revision process as merely a time to correct mechanical and spelling errors, failing to realize the importance of revising and refining content (Scardamalia \& Bereiter, 1986). For example, Graham, Schwartz and MacArthur (1993) found that $61 \%$ of students with LD corrected only the mechanical aspects of their papers compared to $37 \%$ of students who are typically achievers. To make matters more complicated, there are other elements to consider during the revision process such as unity, development, order, clarity, emphasis, and diction. The revision phase of writing should be viewed as a recursive process that takes place during writing, rewriting, reading, and rereading.

Much of time spent by teachers in teaching writing to students has traditionally been devoted to handwriting, spelling, and grammar. Although these are important prerequisites, more is needed to improve the performance of students with LD who have difficulties writing. With respect to writing skills, students with LD are at a significant disadvantage compared to their peers. These students require more extensive strategies and explicit instruction to learn skills and processes that other students learn more easily (Chalk, Hagan-Burke \& Burke, 2005). 


\section{Self-Regulated Strategy Development}

One empirically validated method for teaching strategies is the Self-Regulated Strategy Development (SRSD) approach (see Harris \& Graham, 1992). The primary focus of SRSD is teaching students strategies for successfully completing an academic task. SRSD is based on the belief that the development of self-regulation processes is an important part of learning and maturing and that self-regulatory mechanisms can be fostered and improved through instruction (Harris, Graham, Mason \& Saddler, 2002).

The major goals of SRSD as it relates to writing include helping writers (a) master the higher-level cognitive processes involved in writing; (b) develop autonomous, reflective, selfregulated use of effective writing strategies; and (c) form positive attitudes about writing and about themselves as writers (Harris, 1982).

Over 30 studies conducted on writing instruction for students with disabilities have utilized SRSD to support writing improvements. The results of these studies suggest that SRSD had a strong impact on improving writing performance of upper-elementary and middle school students (typical effect sizes of .80) in four areas: quality, writing knowledge, approach to writing, and self-efficacy (Harris, Graham \& Mason, 2003). SRSD has been used successfully to validate strategies for several elements of the writing process, including brainstorming (Harris \& Graham, 1985), semantic webbing (MacArthur, Schwartz, Graham, Molloy \& Harris, 1996), and revising (MacArthur, Graham \& Schwartz, 1991). In addition, improving performance in planning has also been explored (Chalk et al., 2005; Sexton, Harris, \& Graham, 1998; Troia, \& Graham, 2002).

Several meta-analyses have established the effectiveness of SRSD among students with LD and other struggling writers. For example, Graham and Perrin (2007) reported that SRSD had a strong and positive impact on the quality of writing with students in Grades 4 through 12. The average weighted effect size (based on eight large-group studies) was 1.14. Graham and Harris (2003) reported similar effect sizes for studies with students with LD. Additionally, there is now an emerging body of literature suggesting that SRSD is effective for young struggling writers (Graham, Harris \& Mason, 2005; Harris, Graham \& Mason, 2006). However, there is little data available on secondary school learning-disabled students who learn English as a foreign language. The aim of the current study was to examine the effec- 
tiveness of a program based on self-regulated strategy development on the writing skills of writing disabled secondary school students

\section{Purpose of Current Study}

The purpose of the present study was to determine the effectiveness of the SRSD model with first year secondary school students in Egypt, who were identified as having learning disabilities. The study was designed to provide a systematic replication of the work of Graham and Harris (1989), Chalk et al. (2005) using an updated version of the SRSD model. Similar to Graham and Harris's investigation, scaffolding was provided for students to learn the target strategy, a six-step instructional procedure was followed, and self-regulatory techniques were taught. However, in the present study, students were not only evaluated in terms of the number of words written, but also on the quality of their writing. Similar to Chalk et al. (2005), the current study focused on high school students with learning disabilities.

\section{Method}

\section{Participants}

Sixty-seven students identified with LD were invited to participate. Each student participant met the following established criteria to be included in the study: (a) a diagnosis of LD by teacher referral and learning disabilities screening test (Mourad Ali, in press), (b) an IQ score on the Mental Abilities Test (Mosa, 1989) between 90 and 118, (c) writing performance scores at least 2 years below grade level, and (d) absence of any other disabling condition. The sample was randomly divided into two groups; experimental ( $\mathrm{n}=34 ; 20$ boys and 14 girls) and control ( $\mathrm{n}=33,20$ boys, 13 girls).

The two groups were matched on age, IQ, and writing performance. Table 1 shows means, standard deviations, t-value, and significance level for experimental and control groups for age (by month), IQ, and writing performance (pre-test). 
Table 1. Standard deviations, $t$ - value, and significance level for experimental and control groups for age (by month), IQ, and writing performance (pre-test)

\begin{tabular}{cllclll}
\hline Variable & Group & N & M & SD & T & Sig. \\
\hline Age & Experimental & 34 & 169.66 & 1.96 & -.081 & Not sig. \\
& Control & 33 & 169.70 & 2.01 & & \\
IQ & Experimental & 34 & 113.93 & 4.45 & -.251 & Not sig. \\
& Control & 33 & 114.20 & 4.24 & & \\
\multirow{2}{*}{ Writing } & Experimental & 34 & 17.21 & 3.00 & -.587 & Not sig. \\
& Control & 33 & 17.67 & 3.52 & & \\
\hline
\end{tabular}

Table 1 shows that t-values did not reach the significance level. This indicated that the two groups did not differ in age, IQ, and writing performance (pre-test).

\section{Setting}

The study took place in a secondary school in Baltim sector, Kafr El Sheik Governorate, Egypt. The school had a population of 1,800 students, distributed in first, second and third year.

\section{Procedure}

The students were trained using a self-regulated development strategy to improve their writing skills. Students received 3 training sessions a week, lasting between 40 and 45 minutes. Similar to previous studies, students with LD were provided with a scaffolded strategy for planning essays and self-regulation of the strategy and writing process. The SRSD strategy consisted of six steps as outlined below.

Step 1: Develop background knowledge. The first stage of the SRSD strategy was to establish skills the students would need prior to learning the strategy. Instruction began with activities focused on defining, identifying, and generating the basic parts of an essay. Mnemonics have been used in previous research to help the students remember these components so that they will have a prompt to guide them through the writing process (Graham \& Harris, 1989; Sex- 
ton, Harris, \& Graham, 1998). A chart with the mnemonic device (DARE) was provided as a prompt for the basic framework of an essay. The mnemomic device stands for (a) develop topic sentence, (b) add supporting detail, (c) reject arguments from the other side, and (e) end with a conclusion. Each step of the mnemonic device was explained and discussed as a group. Students practiced reciting DARE together and independently until they could recall it completely from memory. They were then guided by the teacher to determine details for a given topic and practice rejecting opposing arguments.

Step 2. Initial conference: Strategy goals and significance. The teacher reviewed the baseline probe scores with each student individually. This included examining the language arts scoring guidelines of the rubric used to score essay quality and the number of words written. The teacher explained the significance of setting goals and including all the basic components of an essay in their writing. Together, each student and teacher discussed the baseline results, which were provided numerically and graphed, to determine whether the content and amount of content were sufficient. The students were asked to keep a folder with all of their essays and a graph plotting their performance. They were allowed to retain their writing folder for future use and reference after the study.

The primary variables of interest were number of words written and quality scores based on a scoring rubric used by the school district. Target goals for the instructional period were discussed and the criterion was established. Each student had varying target goals, depending on their performance. The goals were set at a minimum of a $25 \%$ increase on the number of words written. Students also set goals to improve the quality of their writing by earning at least two additional points on their quality score.

Students were introduced to the self-regulated strategy model by the use of a poster secured to the chalkboard. This visual prompt listed the three-step writing strategy: (a) Think, who will read this and why am I writing it; (b) Plan what to say using DARE; and (c) Write and say more. The strategy required students to think about their audience and the circumstances in which their essays would be read. It also provided them with an outline for their essay. The teacher began by explaining the components of the strategy and why each is important to their writing. Commitment to use the strategy was expressed by all participants. 
Step 3: Modeling of the strategy. The three-step strategy was reviewed. One of the chosen essay topics was then read to the students. Utilizing the overhead projector, the teacher modeled the strategy by using a "think aloud" technique. As the essay was written, the teacher would constantly ask questions aloud to model what students should do themselves when they write. When the essay was completed, the purpose of self-instruction was introduced. The four main types as suggested by Graham and Harris (1989) were discussed: problem definition, planning, self-evaluation, and self-reinforcement.

Step 4: Memorization of the strategy. The students were given time to practice memorizing the three-step strategy and DARE. As part of the process, they were required to make a visual aid that they could keep in their writing folder to use as a prompt. In addition, they had to memorize the steps by either reciting them to the teacher or writing them on a sheet of paper. Students recorded the self-instruction statements in their writing folder and generated examples of each step. Examples of self-instruction questions included (a) problem definition ("What do I need to do?"); (b) planning ("OK, first I need to"); (c) self-evaluation ("Did I say what I really believe?"); and (d) self-reinforcement ("Great, this is a good reason") (Sexton, Harris \& Graham, 1998).

Step 5: Collaborative practice. Using the visual aids of the three-step strategy and DARE as prompts, the students and the teacher wrote an essay using the overhead projector. The teacher led the direction of the composition, but otherwise it was mainly written from student input. Self-instruction procedures were used and encouraged. During this step, the responsibility of writing shifted from the teacher to the students. Individual student goals were reviewed at this time and modified as needed.

Step 6: Independent practice. The students composed two essays independently. Visual prompts were made available, but the students were encouraged to use them only if they felt it was necessary. Positive praise and feedback were given, but were diminished gradually.

A maintenance probe chosen from the randomly assigned essays was administered twenty-eight days after post-testing. The goal of cognitive strategy instruction is to not only apply the strategy during the class where it is prompted, but to effectively use it in the future as well as across settings and subject matter. 
Design and Analysis

The effects of implementing the SRSD on students' writing performance were assessed using a repeated-measures design, pre- post- and sequential testing.

\section{Instructional Validity}

In order to ensure that all procedures were implemented as planned, the following two protocols were followed. The teacher was knowledgeable about the writing skills expected of students in first year secondary. Lesson plans and writing passages were developed based on his expertise in the area of writing.

\section{Results}

Table 2 shows data from an ANCOVA analysis for the differences in mean post-test scores between experimental and control groups on the Writing test. The table shows that the (F) value was (132.872) and it was significant at the level (0.01).

Table 2. ANCOVA analysis for the differences in mean post-test scores between experimental and control groups on a writing test.

\begin{tabular}{cccccc}
\hline Source & $\begin{array}{c}\text { Type } 111 \\
\text { sum of }\end{array}$ & df & $\begin{array}{c}\text { Mean } \\
\text { square }\end{array}$ & F & Sig. \\
& squares & & & & \\
\hline PRE & 907 & 1 & 907 & & \\
GROUP & 2029,969 & 1 & 2029.969 & 132.872 & 0.01 \\
ERROR & 977.771 & 64 & 15.278 & & \\
TOTAL & 3013.194 & 66 & & & \\
\hline
\end{tabular}

Table 3 shows T-test results for the differences in mean post-test scores between experimental and control groups on the Writing test. The table shows that the $(t)$ value was (14.462). This value is significant at the level (0.01) in favor of the experimental group. The table also shows that there are differences in post-test mean scores between experimental and control groups on the writing test in favor of the experimental group. 
Table 3. T-test results for the differences in mean post-test scores between experimental and control groups on a writing test

\begin{tabular}{rrrrrr}
\hline Group & $\mathrm{N}$ & Mean & Std. deviation & $\mathrm{T}$ & Sig. \\
\hline Experimental & 34 & 33.45 & 3.40 & 14.462 & 0.01 \\
Control & 33 & 17.63 & 2.94 & & \\
\hline
\end{tabular}

Table 4 shows data on a repeated measures analysis for the writing test. The table shows that there are statistical differences between measures (pre-, post-, sequential) at the level (0.01).

Table 4. Repeated measures analysis for the writing test

\begin{tabular}{|c|c|c|c|c|c|}
\hline Source & $\begin{array}{c}\text { Type } 111 \text { sum of } \\
\text { squares }\end{array}$ & $\mathrm{df}$ & Mean square & $\mathrm{F}$ & Sig. \\
\hline Between groups & 6323.974 & 1 & 6323.974 & 240.362 & 0.01 \\
\hline Error 1 & 1710.165 & 65 & 26.310 & & \\
\hline Between Measures & 3743.818 & 2 & 1871.909 & 319.483 & 0.01 \\
\hline Measures x Groups & 3827.121 & 2 & 1913.561 & 326.591 & 0.01 \\
\hline Error 2 & 761.695 & 130 & 5.859 & & \\
\hline
\end{tabular}

Table 5 shows data on the Scheffe test for multi-comparisons on the writing test. The table shows that there are statistical differences between pre and post measures in favor of the post test, and between pre and sequential measures in favor of the sequential test, but no statistical differences between post and sequential tests.

Table 5. Scheffe test for multi-comparisons on the writing test

\begin{tabular}{lccc}
\hline \multicolumn{1}{c}{ Measure } & Pre $(\mathrm{M}=17.01)$ & Post $(\mathrm{M}=33.45)$ & Sequential $(\mathrm{M}=32.35)$ \\
\hline Pre & - & - & - \\
Post & $18.95^{*}$ & - & - \\
Sequential & $17.85^{*}$ & 1.10 & - \\
\hline
\end{tabular}




\section{Discussion}

The main objective of the present study was to explore whether there were differences in mean post-test scores between control and experimental groups in writing achievement. The study also examined if the programme was effective, and if this effect was still evident a month later. The results of this study as revealed in Tables 3 and 5 show that the SelfRegulated Strategy Development (SRSD) was effective in improving the writing performance of students in the experimental group, as compared to the control group, whose members received conventional teaching.

Participants of this study meet the minimum IQ of 90; nevertheless, they have learning disability. The IQ score, therefore, cannot account for learning disabilities. The results of the present study support with evidence the conclusion that students who participated do not fall into the low IQ range; however, they have learning disabilities. When designing a program based on Self-Regulated Strategy Development, they had a statistically significant increase in word recognition and comprehension skills. This goes in line with a problem noted by Mourad Ali, Waleed, and Ahmed (2006), that "students who are identified as learning disabled often cover up any special abilities and talents, so that their weakness becomes the focus of their teachers and peers, and their abilities are ignored. Mourad Ali (2007), however, notes that "the learning disabled, as well as gifted students, can master the same contents and school subjects", but they need to do so in a way that is different from what is being followed in our schools.

The experimental group gained better scores on the post-tests on writing performance than did the control group, though there were no statistical differences between the two groups in pre-tests. This result shows that the program met the experimental group's needs and interests. On the contrary, the control group was left to be taught traditionally. That is, the individuals in this group did not receive the same instruction which adopted the SRSD model. This goes in line with our perspective that traditional methods used in our schools do not direct students as individuals toward tasks and materials, and do not challenge their abilities. This may lead students to hate all subjects and the school in general. The contrary occurs when teachers adopt a model (such as The Self-Regulated Strategy Development) that suits student interests and challenges their abilities with its various modalities. 
As we learn more about the scope and complexity of individual differences and how they affect academic progress, we become increasingly convinced that many individuals who do not write well do not do so because the instructional methods used to teach them do not match their preferred learning styles. We should therefore seek strategies that help these students and make use of their strengths. Students need to be self regulated learners. Nevertheless "it is difficult to make use of self regulation skills if they are not offered suitable conditions for excercising autonomy" (Rochera \& Naranjo, 2007, p. 807).

Worth mentioning is that students in the experimental group retained the information learnt for a long time, even after the period of the program finished, and this indicates the training effect. And this indicates that "self regulated learning is an acquired process and can be improved" (De la Fuente \& Justicia, 2007, p. 539).

Study findings go in the same line as most studies that have adopted the SelfRegulated Strategy Development (SRSD) model, for example in increasing the story-writing ability of Young Writers with Learning Disabilities (Saddler, 2006), and the writing process of high school students with learning disabilities (Chalk et al., 2005; Graham et al., 2005; Harris et al., 2006). 


\section{References}

Barenbaum, E., Newcomer, P., \& Nodine, B. (1987). Children's ability to write stories as a function of variation in task, age, and developmental level. Learning Disability Quarterly, 7, 175-188.

Burtis, P., Bereiter, C., Scardamalia, M. \& Tetroe, J. (1983). The development of planning in writing. In G. Wells \& B. Kroll (Eds.), Explorations in the development of writing. Chichester, England: John Wiley.

Chalk, J., Hagan-Burke, S. \& Burke, M. (2005). The Effects of Self-Regulated Strategy Development on the Writing Process for High School Students with Learning Disabilities. Learning Disability Quarterly, 28(1), pp. 75- 87.

Danoff, B., Harris, K.R., \& Graham, S. (1993). Incorporating strategy instruction within the writing process in the regular classroom: Effects on the writing of students with and without learning disabilities. Journal of Reading Behavior, 25, 295-322

De la Fuente, J. \& Justicia, F. (2007). The DEDEPRO ${ }^{\mathrm{TM}}$ Model of Regulated Teaching and Learning : recent advances. Electronic Journal of Research in Educational Psychology, 13, 5(3), 535-564.

De La Paz, B., \& Graham, S. (1997). Strategy instruction in planning: Effects on the writing performance and behavior of students with learning difficulties. Exceptional Children, 63, 167-181.

Englert, C. S., \& Mariage, T. V. (1991). Shared understandings: Structuring the writing experience through dialogue. Journal of Learning Disabilities, 24, 330-342.

Harris, K. R., Schmidt, T. and Graham, S. (1997). Every Child Can Write: Strategies for Composition and Self-Regulation in the Writing Process. Retrieved from LD Online, $1-38$.

Graham, S. (1990). The role of production factors in learning disabled students' compositions. Journal of Educational Psychology, 82, 781-791.

Graham, S. \& Harris, K. R. (1989). Improving learning disabled students' skills at composing essays: Self-instructional strategy training. Exceptional Children, 56, 201- 214.

Graham, S., \& Harris, K. R. (1996). Teaching writing strategies within the context of a whole language class. In E. McIntyre \& M. Pressley (Eds.), Balanced instruction: Strategies and skills in whole language (pp. 155-175). New York: Christopher- Gordon.

Graham, S. \& Harris, K. R. (2003). Students with learning disabilities and the process of writing: A meta-analysis of SRSD studies. In H. L. Swanson, K. R. Harris \& S. Gram. Eds.), Handbook of learning disabilities (pp. 323-344). New York: The Guilford Press 
Graham, S., \& Perin, D. (2007). A meta-analysis of writing instruction for adolescent students. Journal of Educational Psychology, 99, 445-476

Graham, S., Harris, K. R., \& Mason, L. (2005). Improving the writing performance, knowledge, and self-efficacy of struggling young writers: The effects of self-regulated strategy development. Contemporary Educational Psychology, 30, 207-241.

Graham, S., Harris, K. R., MacArthur, C. A., \& Schwartz, S. S. (1991). Writing and writing instruction with students with learning disabilities: A review of a program and research. Learning Disability Quarterly, 14, 89-114.

Graham, S., MacArthur, C., \& Schwartz, S. (1995). Effects of goal setting and procedural facilitation on the revising behaviour and writing performance of students with writing and learning problems. Journal of Educational Psychology, 87(2), 230-240.

Graham, S., Schwartz, S., \& MacArthur, C. (1993). Learning disabled and normally achieving students' knowledge of the writing and the composing process, attitude toward writing, and self-efficacy. Journal of Learning Disabilities, 26, 237-249.

Graham, S., MacArthur, C., Schwartz, S., \& Voth, T. (1992). Improving the compositions of students with learning disabilities using a strategy involving product and process goal setting. Exceptional Children, 58, 322-335

Harris, K.R. (1982). Cognitive-behavior modification: Application with exceptional. Focus on Exceptional Children, 15(2), 1-16

Harris, K.R., \& Graham, S. (1985). Improving learning disabled students= composition skills: Self-control strategy training. Learning Disability Quarterly, 8, 27-36

Harris, K.R., Graham, S., \& Mason, L. (2003). Self-regulated strategy development in the classroom: Part of a balanced approach to writing instruction for students with disabilities. Focus on Exceptional Children, 35(7), 1-16

Harris, K.R., Graham, S., \& Mason, L. (2006). Improving the writing, knowledge, and motivation of struggling young writers: Effects of self-regulated strategy development with and without peer support. American Educational Research Journal, 43(2), 295-340

Harris, K.R., Graham, S., Mason, L.H., \& Saddler, B. (2002). Developing self-regulated writers. Theory Into Practice, 41, 110-115.

Kline, F. M., Schumaker, J. B., \& Deshler, D. D. (1991). Development and validation of feedback routines for instructing students with learning disabilities. Learning Disability Quarterly, 14, 191-207. 
MacArthur, C., \& Graham, S. (1987). Learning disabled students' composing under three methods of text production: Handwriting, word processing, and text production. Journal of Special Education, 21, 22-42.

MacArthur, C. A., Graham, S., \& Skarvold, J. (1986). Learning disabled students composing with three methods: Handwriting, dictation, and word processing (Technical Report \#109). College Park, MD: Institute for the Study of Exceptional Children and Youth.

MacArthur, C. A., Schwartz, S. S., \& Graham, S. (1991). Effects of a reciprocal peer revision strategy in special education classrooms. Learning Disability Research, 6, 201-210.

MacArthur, C. A., Graham, S., Schwartz, S. S., \& Schafer, W. D. (1995). Evaluation of a writing instruction model that integrated a process approach, strategy instruction, and word processing. Learning Disabilities Quarterly, 18, 278-291.

MacArthur, C., Schwartz, S., Graham, S., Molloy, D., \& Harris, K.R. (1996). Integration of strategy instruction into a whole language classroom: A case study. Learning Disabilities Research and Practice, 11(3), 168-176.

Mourad Ali, E. (2007). How the writing disabled brain learns, Alexandrai, Dar EL Wafaa.

Mourad Ali, E. (In press). A scale for screening high adolescent students with learning disabilities, Alexandrai, Dar EL Wafaa.

Mourad Ali, E., Fadlon Saad, E. (2007). The effectiveness of a program based on the self regulated strategy development on writing performance, writing self -efficacy and attributions of writing disabled first year secondary school students, Journal of education and psychology, Tanta university, 38(2), pp 75-93.

Mourad Ali, E., Waleed El sayed \& Ahmed Gomaa (2006). Computer and learning disabilities, theory and practice, Alexandria, Dar El Wafaa

Newcomer, P., Nodine, B., \& Barenbaum, E. (1988). Teaching writing to exceptional children: Reaction and recommendations. Exceptional Children, 54, 559-564.

Rochera, M. J. \& Naranjo, M. (2007). Fostering self regulated learning in an assessment situation . Electronic Journal of Research in Educational Psychology, 13, 5(3), 805-824

Saddler, B. (2006). Increasing Story-Writing Ability through Self-Regulated Strategy Development: Effects on Young Writers with Learning Disabilities. Learning Disability Quarterly, 29, 291- 316.

Scardamalia, M., \& Bereiter, C. (1986). Research on written composition. In M. C. Wittrock (Ed.), Handbook of research on teaching (3rd ed., pp. 778-803). New York: McMillan. 
Sexton, M., Harris, K. R., \& Graham, S. (1998). Self-regulated strategy development and the writing process: Effects on essay writing and attributions. Exceptional Children, 64(3), 295-311.

Thomas, C., Englert, C., \& Gregg, S. (1987). An analysis of errors and strategies in the expository writing of learning disabled students. Remedial and Special Education, 8, 21-30.

Troia, G., \& Graham, S. (2002). The effectiveness of a highly explicit, teacher-directed strat egy instruction routine: Changing the writing performance of students with learning disabilities. Journal of Learning Disabilities, 35, 290-305.

Wong, B., Butler, D., Ficzere, S., Kuperis, S., Corden, M., \& Zlmer, J. (1994). Teaching problem learners revision skills and sensitivity to audience through two instructional modes: Student-teacher versus student-student interactive dialogues. Learning Disabilities Research and Practice, 9, 78-90. 